\title{
SATISFACTION WITH PENILE APPEARANCE AFTER HYPOSPADIAS SURGERY: THE PATIENT AND SURGEON VIEW
}

\author{
MARC A. M. MUREAU, FROUKJE M. E. SLIJPER, A. KOOS SLOB, FRANK C. VERHULST AND \\ RIEN J. M. NIJMAN
}

\begin{abstract}
From the Departments of Child and Adolescent Psychiatry and Pediatric Urology, Sophia Children's Hospital, University Hospital Rotterdam, Department of Plastic and Reconstructive Surgery, Dijkzigt Hospital, and Department of Endocrinology and Reproduction, Faculty of Medicine and Health Sciences, Erasmus University Rotterdam, Rotterdam, The Netherlands
\end{abstract}

\section{ABSTRACT}

Purpose: We studied the degree of agreement between hypospadias patient and surgeon satisfaction with the cosmetic surgical result, and the relation between penile length, meatal position and patient satisfaction.

Materials and Methods: Cosmetic and functional results in 35 boys with hypospadias were assessed, and a standardized questionnaire was completed by patients and surgeon.

Results: There was hardly any agreement between patient and surgeon satisfaction with patient penile appearance. Patients were less satisfied than the surgeon. No significant correlation was noted between penile satisfaction and penile length. Patients with a retracted meatus were less satisfied with the meatal position than those with a glanular meatus. Of the 35 patients 4 underwent repeat surgery after our study.

Conclusions: Hypospadias surgeons should explicitly ask if patients are satisfied and they should follow patients through adolescence.

\section{KEY WORDS: penis; hypospadias; surgery, plastic}

Corrective surgery of hypospadias, that is reconstructing the urethra and straightening the penis, is necessary to ensure voiding in the standing position and unhampered adult sexual functioning. Another important goal of hypospadias surgery is the achievement of a cosmetic penile appearance that is as normal as possible. Others who studied long-term results of hypospadias surgery reported patient satisfaction with the penile appearance or surgeon satisfaction with the surgical result. ${ }^{1-6}$ To our knowledge only Schwöbel et al have previously assessed hypospadias patient and surgeon satisfaction with the cosmetic result. ${ }^{7}$ of the 27 patients $92 \%$ judged the cosmetic result to be satisfactory or excellent and all had a satisfactory or excellent cosmetic result, as judged by Schwöbel et al.? Unfortunately, from these data it is impossible to determine the degree of agreement between patient and surgeon satisfaction, and only the position of the urethral meatus was considered in judging the surgical result.

These previous studies made no distinction between satisfaction with functional result and cosmetic penile appearance. It was not known if hypospadias patients were satisfied with the same aspects of penile appearance as the surgeon. It seems essential to know whether hypospadias patients and surgeons consider the same aspects of penile appearance to be important to determine if patient treatment or counseling should be adjusted. Therefore, we evaluated in a standard manner the level of agreement between hypospadias patient and surgeon satisfaction with different aspects of patient penile appearance, and the relation between physical genital characteristics (penile length and meatal position) and satisfaction with penile appearance in hypospadias patients.

\section{PATIENTS AND METHODS}

Patients. Of the $\mathbf{4 5 8}$ patients treated for hypospadias between 1980 and 1992 at the Sophia Children's Hospital 113 who were 9 to 18 years old at the onset of our study previ-

Accepted for publication June 23, 1995.

Supported by the Sophia Foundation for Medical Research. ously underwent terminal procedures, which split, core or tunnel through the glans to create a true terminal glanular meatus. ${ }^{8-13}$ Of these 113 boys 86 had distal and 27 had proximal hypospadias and the latter were included in our study. To obtain an approximately equal group with distal hypospadias and because of lack of time, only 33 patients were randomly selected from the $\mathbf{8 6}$ with distal hypospadias. Thus, 60 boys were included in our study.

Invitations to participate. From November 1993 to May 1994 patients and parents received a letter explaining the purpose of the study, which is part of a larger study on psychosexual and psychosocial adjustment of hypospadias patients, and inviting them to participate. About a week later they were telephoned to determine if they would present to the hospital.

Instruments. A standardized questionnaire was administered consisting of 8 items about different aspects of the genitals (see Appendix). Satisfaction with each genital aspect was rated on a 4-point scale ranging from 1-very dissatisfied to 4-very satisfied. A genital perception score was calculated by totaling the raw scores of the 8 items, ranging from 8-very dissatisfied to 32-very satisfied with genital appearance. In addition to the hypospadias patients who completed this questionnaire independently, the surgeon (a pediatric urologist) rated his/her satisfaction with the penile appearance on an identical questionnaire.

Physical examination. With the patient in a supine position penile length was measured from the pubic bone to the tip of the glans with a cotton swab, which was held along the dorsal side of the stretched penis and marked at the level of the penile top. Subsequently the length of the cotton swab was measured with a ruler. The position of the meatus was marked on a schematic drawing of a penis. From these markings 2 meatal positions were scored (1-glanular and 2 -coronal).

Statistical methods. We used Student's t, Mann-Whitney U (corrected for ties) and Wilcoxon matched pairs signed rank tests, Spearman's rank ( $r_{s}$, corrected for ties), Pearson's ( $r$ ) 
and partial $\left(r_{p}\right)$ correlation coefficients, and binomial tests. 14 Statistical significance was considered at $p<0.05$ (2-tailed unless otherwise indicated).

\section{RESULTS}

Response. Of the 60 children and adolescents with hypospadias 3 were lost to followup and $35(61.4 \%)$ presented to the hospital for physical examination. A questionnaire was completed for these 35 boys. Since the percent of patients for whom questionnaires were completed was rather low, a selection bias could have occurred. Therefore, several sample characteristics of the responders and nonresponders were compared. Participating patients did not significantly differ from nonresponders in regard to mean age at the present study, severity of hypospadias, surgical procedure, mean age at final surgery and mean number of operations (table 1). Thus, we assume that the participating patients are a representative sample.

Differences in satisfaction between patients and surgeon. As indicated by a lower genital perception score, children and adolescents with hypospadias were less satisfied than the pediatric urologist with the overall genital appearance, mainly penile and glanular size and shape but also the appearance of the scrotum and testes (table 2). After excluding patients who were also treated for cryptorchidism (3 of 35) the other 32 remained less satisfied with the appearance of the scrotum and testes than the surgeon (Wilcoxon matched pairs signed rank test, $\mathrm{z}=-3.68, \mathrm{p}<0.001$ ).

Agreement of satisfaction between hypospadias patients and surgeon. Table 3 shows Spearman's rank correlation coefficients between hypospadias patient and surgeon satisfaction with several genital aspects. In general, there was hardly any agreement except for satisfaction with scars.

Physical characteristics. Mean stretched penile length of the children and adolescents was $8.4 \pm 2.5 \mathrm{~cm}$. (range 3 to 15). Significantly more patients $(21.2 \%$, binomial test, 1-tailed $p=0.032$ ) were below the 10th percentile for stretched penile length, as reported by Schonfeld and Beebe (table 4). ${ }^{15} \mathrm{~A}$ high correlation coefficient existed in 33 boys between age and penile length $(r=0.76, p<0.001)$. Since there were no statistically significant differences in mean age (Student's $t$ test, $t(35)=0.25, p=0.808$ ), the comparison of penile length between those with distal and proximal hypospadias was not statistically controlled for age. This analysis revealed no significant differences between patients with distal (mean $8.6 \mathrm{~cm}$.) and proximal hypospadias (mean 8.2 $c m$., Student's $t$ test, $t(31)=0.42, p=0.679$ ). The urethral meatus was in a glanular position in 24 patients $(68.6 \%)$ and a coronal position in 11 (31.4\%).

Relation between physical characteristics and satisfaction with penile appearance. Because there was significant correlation between patient age and penile length, the correlation between the genital perception score and penile length was controlled for age. Unexpectedly there did not exist a positive and statistically significant correlation between penile length and patient genital perception score $\left(r_{p}=-0.31,29\right.$ $\mathrm{df}, \mathrm{p}=0.091$ ). The 7 boys who were below the 10 th percentile
TABLE 2. Satisfaction with penile appearance of 35 children and adolescents with hypospadias 9 to 18 years old, as judged by patients and pediatric urologist (Wilcaxon matched pairs signed rank test)

\begin{tabular}{|c|c|c|c|c|c|}
\hline & \multicolumn{2}{|c|}{ Mean Values \pm SD } & \multirow{2}{*}{$\begin{array}{l}\text { No. } \\
\text { Pairs }\end{array}$} & \multirow{2}{*}{$\begin{array}{c}2 \\
\text { Value }\end{array}$} & \multirow{2}{*}{$\stackrel{p}{\text { Value }}$} \\
\hline & Pts. & Urologist & & & \\
\hline \multicolumn{6}{|l|}{ Satisfaction with:* } \\
\hline Flaccid penile size & $3.1 \pm 1.1$ & $3.9 \pm 0.4$ & 35 & -3.34 & 0.0008 \\
\hline Penile thickness & $3.1 \pm 0.9$ & $3.9 \pm 0.3$ & 35 & -4.01 & 0.0001 \\
\hline Glanular size & $3.1 \pm 1.0$ & $3.9 \pm 0.3$ & 35 & -3.64 & 0.0003 \\
\hline Glanular shape & $3.1 \pm 0.9$ & $3.5 \pm 0.6$ & 35 & -2.31 & 0.0207 \\
\hline Position of meatus & $3.6 \pm 0.7$ & $3.4 \pm 0.7$ & 35 & -1.27 & 0.2049 \\
\hline Scars & $2.8 \pm 1.3$ & $3.2 \pm 0.7$ & 33 & -1.82 & 0.0680 \\
\hline Scrotum/testes & $3.3 \pm 0.8$ & $3.9 \pm 0.2$ & $\mathbf{3 5}$ & $-\mathbf{3 . 7 0}$ & 0.0002 \\
\hline General penile appearance & $3.0 \pm 1.0$ & $3.4 \pm 0.6$ & 35 & -1.72 & 0.0853 \\
\hline Genital perception score $†$ & $25.1 \pm 6.1$ & $29.1 \pm 2.5$ & 33 & -3.26 & 0.0011 \\
\hline
\end{tabular}

TABLE 3. Agreement between satisfaction of surgeon and 35 hypospadios patients 9 to 18 years old regarding several aspects of genitals (Spearman's rank correlation coefficients)

\begin{tabular}{lccc}
\hline & $\begin{array}{c}\text { Spearman's Rank } \\
\text { Correlation Coeficient }\end{array}$ & No. Pts. & p Value \\
\hline Flaccid penile size & 0.17 & 35 & 0.340 \\
Penile thickness & 0.28 & 35 & 0.106 \\
Glanular size & 0.08 & 35 & 0.644 \\
Glanular shape & 0.30 & 35 & 0.084 \\
Position of meatus & 0.29 & 35 & 0.088 \\
Scars & 0.53 & 33 & 0.002 \\
Scrotumitestes & -0.23 & 35 & 0.186 \\
General penile appearance & -0.07 & 35 & 0.686 \\
Genital perception score & 0.31 & 33 & 0.078 \\
\hline
\end{tabular}

TABLE 4. Stretched penile length of 35 hypospadias patients compared to normative data by age

\begin{tabular}{|c|c|c|c|}
\hline \multirow{2}{*}{$\begin{array}{l}\text { No. - Age } \\
\text { Pts. (yrs.) }\end{array}$} & \multirow{2}{*}{$\begin{array}{l}\text { Cm. Stretched } \\
\text { Penile Length }\end{array}$} & \multicolumn{2}{|c|}{ Cm. Stretched Penile Length ${ }^{15}$} \\
\hline & & 10th Percentile & 90th Percentile \\
\hline $5-9$ & $5,5.5,6,8,8$ & 4.9 & 7.6 \\
\hline $3-10$ & $6.5,7,9$ & 4.9 & 7.6 \\
\hline $6-11$ & $3, * 5,5.5,6,7,8$ & 4.7 & 8.7 \\
\hline $2-12$ & $7.5,8$ & 4.9 & 11.3 \\
\hline $3-13$ & $6, * 7,10$ & 6.1 & 12.2 \\
\hline $4-14$ & $8,10,11,12$ & 6.6 & 13.5 \\
\hline $3-15$ & $9, * 10,10.5$ & 9.1 & 14.8 \\
\hline $4-16$ & $10 * 10, * 10 * 11$ & 10.8 & 15.3 \\
\hline $2-17$ & 12,15 & 10.8 & 15.3 \\
\hline $1-18$ & $10^{*}$ & 10.8 & 15.5 \\
\hline
\end{tabular}

* Below the 10th percentile.

for stretched penile length were equally satisfied with flaccid penile size as the 26 boys above the 10th percentile (MannWhitney $U$ test, $z=0$ ). Patients with a glanular meatal position reported more satisfaction with the position of the meatus than those with a coronal meatal position (MannWhitney $\mathrm{U}$ test, $\mathrm{z}=-2.39,35$ boys, $\mathrm{p}=0.017$ ).

Repeat surgery. After the physical examination in our

TABLE 1. Sample characteristics of 35 responders and 25 nonresponders among 9 to 18-year-old hypospadias patients

\begin{tabular}{|c|c|c|c|c|}
\hline & Responders & Nonresponders & & p Value \\
\hline $\begin{array}{l}\text { Mean age at present study } \pm \text { SD (yrs.) } \\
\text { Severity of hyposadias: }\end{array}$ & $13.2 \pm 2.7$ & $\overline{14} \pm 2.7$ & $t=-1.17$ & 0.250 \\
\hline $\begin{array}{l}\text { Distal } \\
\text { Proximal }\end{array}$ & $\begin{array}{l}18(51.4 \%) \\
17(48.6 \%)\end{array}$ & $\begin{array}{l}15(60 \%) \\
10(40 \%)\end{array}$ & Chi-square $=0.43$ & 0.514 \\
\hline $\begin{array}{l}\text { Island Alap, }{ }^{12} \text { Perovic }{ }^{13} \\
\text { Mean age at final surgery } \pm \text { SD } \\
\text { Mean No. Operations } \pm \text { SD }\end{array}$ & $\begin{array}{r}17(48.6 \%) \\
7.3 \pm 3.2 \\
2.3 \pm 1.3\end{array}$ & $\begin{array}{l}10(40 \%) \\
7.6 \pm 3.2 \\
2.4 \pm 1.4\end{array}$ & $\begin{array}{l}\mathbf{z}=-0.37 \\
\mathbf{z}=-0.22\end{array}$ & $\begin{array}{l}0.711 \\
0.827\end{array}$ \\
\hline
\end{tabular}


study 4 boys (11\%) underwent repeat surgery due to iatrogenic lateral penile curvature (2), a fistula (1) and a retracted coronal meatus (1). It is of particular interest that these patients stated that they would not have readily consulted a physician for these problems on their own initiative.

\section{DISCUSSION}

We noted hardly any agreement between hypospadias patient and surgeon satisfaction with patient penile appearance. These results corroborate our clinical impression that excellent cosmetic results, as judged by surgeons, do not necessarily lead to patient satisfaction. Conversely patients with poor cosmetic results can be satisfied and not desire further surgery, even when cosmetic improvement is feasible. Therefore, hypospadias surgeons should explicitly ask if the patient is satisfied with the penile appearance. If the patient is not satisfied, the surgeon should inquire about the motive for dissatisfaction and inform the patient whether it would be feasible to improve surgically the penile appearance further.

A striking result is that hypospadias patients were less satisfied with the appearance of the scrotum and testes than the surgeon, even after exclusion of those who were also treated for cryptorchidism. Patients were less satisfied than the surgeon with 5 of the 8 different genital aspects, suggesting that patients have a more negative overall genital perception. This hypothesis is supported by the findings of our study on the genital perception of 116 boys (including the 35 in our present study) as well as 73 adults with hypospadias, who had a significantly more negative overall genital perception than age matched comparison male subjects. ${ }^{16}$

In our present study the mean number of operations and mean age at which treatment was finished were high, which could have negatively affected genital perception of the patients. However, in our previous study we noted no significant relationships between the genital perception of 116 boys with hypospadias (including the $\mathbf{3 5}$ in our present study) and the number of operations or age at which treatment was finished. 16

Approximately a third of those who underwent terminal repair had a retracted coronal meatus, which confirms the results of an earlier study showing partial or complete meatal retraction in $37 \%$ of 41 patients treated by meatal advancement and glanuloplasty. ${ }^{17}$ It contradicts the results of another study in which meatal retraction was present in only $0.6 \%$ of 1,111 patients treated by meatal advancement and glanuloplasty. ${ }^{18}$ However, these results are hardly comparable since the mean followup was much longer in our present study (5.8 years, range 2.3 to 9.2 ) than previous studies ( 29 months and 2.3 months, respectively). ${ }^{17,18}$ Our present study also comprised patients with proximal hypospadias treated by different surgical techniques. Nevertheless, meatal retraction remains a possible long-term complication in hypospadias patients.

Boys with a terminal meatus were more satisfied with the meatal position than those with a retracted coronal meatus, which seems to indicate that it is important for the surgeon to try to achieve a terminal meatus. However, since the position of the meatus was not a major motive for concern in children, adolescents or adults with hypospadias, ${ }^{19.20}$ we recommend performing repeat advancement of a retracted meatus only when the patient desires a terminal meatus or the retracted meatus causes spraying of urine.

Given that the 10th and 90 th percentiles are the ranges of normal variation ${ }^{15}$ in our present study penile underdevelopment was noted about 2 times more often in hypospadias patients than among age matched normal boys. Stretched instead of flaccid penile length was measured since the latter varies appreciably in response to tactile, thermal and other environmental changes, ${ }^{15}$ which makes measuring flaccid length less reliable than stretched length. Therefore, we advise those who study the penile length of hypospadias patients to measure stretched penile length from the pubic bone to the tip of the glans for which reliable normative data exist from birth to maturity. ${ }^{15}$ No difference in penile length was observed between patients with distal and proximal hypospadias, contrary to previous studies, which described a negative correlation between flaccid or stretched penile length and severity of hypospadias.2,21 Although small penile size was the most frequently reported motive for dissatisfaction in children, adolescents and adults with hypospadias, ${ }^{19,20}$ in our present study there was no significant correlation between penile length and patient satisfaction.

\section{CONCLUSIONS}

Although one cannot exclude the possibility that hypospadias patients with problems more often participated in our present study than those without problems, $11 \%$ of the participants underwent repeat surgery after our present study because of the poor long-term functional result of previous surgery. We strongly advocate that hypospadias surgeons follow patients during adolescence as a standard therapeutic procedure since patients may be reluctant to seek medical advice on their own initiative, even when they are experiencing considerable difficulties;2, 19,20 boys with hypospadias are treated at increasingly younger ages (often before 18 months) and, therefore, they are not able to express satisfaction or dissatisfaction with the surgical result; our previous study with children and adolescents showed that adolescents 13 to 18 years old more often desired cosmetic or functional penile improvement than children 9 to 12 years old, ${ }^{20}$ and complications, such as meatal retraction or stenosis, residual penile curvature or adult sexual dysfunction, often become apparent many years after surgical treatment.

APPENDIX: GENITAL PERCEPTION QUESTIONNAIRE FOR HYPOSPADIAS PATIENTS

Satisfaction with the Very A little A little Very appearance of: dissatis- dissatis- satisfied satisfied

Flaccid penile size

Penile thickness

Glanular size

Glanular shape

Position of meatus

Scars

Scrotum/testes

Penile appearance in general fied fied

$\begin{array}{llll}1 & 2 & 3 & 4 \\ 1 & 2 & 3 & 4 \\ 1 & 2 & 3 & 4 \\ 1 & 2 & 3 & 4 \\ 1 & 2 & 3 & 4 \\ 1 & 2 & 3 & 4 \\ 1 & 2 & 3 & 4 \\ 1 & 2 & 3 & 4\end{array}$

\section{REFERENCES}

1. Sommerlad, B. C.: A long-term follow-up of hypospadias patients. Brit. J. Plast. Surg., 28: 324, 1975.

2. Bracka, A.: A long-term view of hypospadias. Brit. J. Plast. Surg., 42: 251, 1989.

3. Eberle, J., Uberreiter, S., Radmayr, C., Janetschek, G., Marberger, H. and Bartsch, G.: Posterior hypospadias: longterm followup after reconstructive surgery in the male direction. J. Urol., 150: 1474, 1993.

4. Kumar, M. V. and Harris, D. L.: A long term review of hypospadiss repaired by split preputial fap technique (Harris). Brit. J. Plast. Surg., 47: 236, 1994.

5. Helmig, F. J.: Langzeitergebnisse nach Hypospadie-Operationen. Klin. Paed., 186: 421, 1974.

6. Beretta, G., Mazzucchelli, S., Zanollo, A., Negri, L. and Catanzaro, F.: Ipospadia: comportamento sessuale in maschi adulti sottoposti a trattamento chirurgico correttivo in eta pediatrica. Minerva Urol. Nefrol., 38: 17, 1986.

7. Schwöbel, M. G., Sacher, P. and Staufier, U. G.: Die Denis- 
Browne-Korrektur der Hypospadie: Langzeitergebnisse. Z. Kinderchir., 42: 157, 1987.

8. Duckett, J. W.: MAGPI (meatoplasty and glanuloplasty): a procedure for subcoronal hypospadias. Urol. Clin. N. Amer., 8: $513,1981$.

9. Zaontz, M. R.: The GAP (glans approximation procedure) for glanular/coronal hypospadias. J. Urol,, 141: 359, 1989.

10. Koff, S. A.: Mobilization of the urethra in surgical treatment of hypospadias. J. Urol., 125: 394, 1981.

11. Mathieu, $P$.: Traitement en un temps l'hypospadias balanique et juxtabalanique. J. Chir., 39: 481, 1932.

12. Duckett, J. W.: The island flap technique for hypospadias repair. Urol. Clin. N. Amer., 8: 503, 1981.

13. Perović, S.: Operationsprinzip bei der penilen Hypospadie. Akt. Urol., suppl., 12: 78, 1981.

14. Altman, D. G.: Practical Statistics for Medical Research. London: Chapman \& Hall, 1991.

15. Schonfeld, W. A. and Beebe, G. W.: Normal growth and variation in the male genitalia from birth to maturity. J. Urol., 48: 759, 1942.

16. Mureau, M. A. M., Slijper, F. M. E., Slob, A. K. and Verhulst, F. C.: Genital perception of children, adolescents, and adults operated on for hypospadias: a comparative study. J. Sex Res., 32: 283, 1995.

17. Unlüer, E. S., Miroglu, C., Ozdiler, E. and Ozturk, R.: Long-term follow-up results of the MAGPI (meatoplasty and glanuloplasty) operations in distal hypospadias. Int. Urol. Nephrol., 23: 581, 1991.

18. Duckett, J. W. and Snyder, H. M., III: Meatal advancement and glanuloplasty hypospadias repair after 1,000 cases: avoidance of meatal stenosis and regression. J. Urol., 147: 665, 1992.

19. Mureau, M. A. M., Slijper, F. M. E., van der Meulen, J. C., Verhulst, F. C. and Slob, A. K.: Psychosexual adjustment of adult men operated for hypospadias: a norm-related study. J. Urol., 154: 1351, 1995.

20. Mureau, M. A. M., Slijper, F. M. E., Nijman, R. J, M., van der Meulen, J. C., Verhulst, F. C. and Slob, A. K.: Psychosexual adjustment of children and adolescents after different types of hypospadias surgery: a norm-related study. J. Urol., 154: 1902, 1995.

21. Figalova, P., Farkaš, L. G. and Hajnis, K.: Eine Studie zur Erforschung somatischer Merkmale bei Patienten mit Hypospadie. Z. Urol., 61: 313, 1968. 